Int. J. Dev. Biol. 55: 547-555

doi: $10.1387 / \mathrm{ijdb} .103230 \mathrm{ml}$

\title{
The use of the orthotopic model to validate antivascular therapies for cancer
}

\author{
MONICA LOI ${ }^{1}$, DANIELA DI PAOLO ${ }^{1}$, PAMELA BECHERINI ${ }^{1}$, ALESSIA ZORZOLI ${ }^{1}$, PATRIZIA PERRI ${ }^{1}$, \\ ROBERTA CAROSIO ${ }^{1}$, MICHELE CILLI ${ }^{2}$, DOMENICO RIBATTI ${ }^{3}$, CHIARA BRIGNOLE ${ }^{1}$, GABRIELLA PAGNAN ${ }^{1}$, \\ MIRCO PONZONI $1, \#, * *$ and FABIO PASTORINO $1, \#, * *$
}

\begin{abstract}
${ }^{1}$ Experimental Therapies Unit, Laboratory of Oncology, G. Gaslini Children's Hospital, Genoa, ${ }^{2}$ Animal Research Facility, National Cancer Institute, Genoa and ${ }^{3}$ Department of Human Anatomy and Histology, University of Bari, Italy

ABSTRACT The orthotopic model reproduces aspects of the tumour microenvironment and emulates a number of important biological features of cancer progression, angiogenesis, metastasis and resistance. Due to its parallels with human cancer, the model can be used to evaluate therapeutic responses to various therapies. This review outlines the importance of using the orthotopic implantation of tumour cells in mice models for evaluating the effectiveness of antivascular therapies.
\end{abstract}

KEY WORDS: orthotopic model, vascular disrupting agent, antivascular therapy, cancer

\section{Tumour vasculature and antivascular therapies}

A functioning and continuously expanding vascular network is essential for tumour development, growth, survival and metastasis (Hanahan and Folkman, 1996). Given its pivotal role in these processes, tumour vasculature is a highly attractive target in anticancer therapy. Compared with the vasculature in normal tissue, the tumour vasculature is strikingly disorganized and tortuous (Eberhard, 2000; Konerding, 2001; McDonald and Choyke, 2003), its wall is poorly developed, often with discontinuous endothelial-cell lining, has relatively poor investiture with vascular smooth muscle cells, poor connections between pericytes and endothelial cells (Dvorak, 1988; Eberhard, 2000; Hashizume, 2000; Kobayashi, 1993) and an irregular, structurally abnormal basement membrane (Baluk, 2003; Paku and Paweletz, 1991). Endothelial cells themselves are often irregularly shaped, forming an uneven luminal layer, with loose interconnections and focal intercellular openings (Hashizume, 2000). These features contribute to a high intrinsic vascular permeability of macromolecules into the vasculature (Dvorak, 1991; Jain, 1987) and the consequent development of high interstitial fluid pressure (Boucher, 1990), which is augmented by inadequate lymphatic drainage. Tumour vascular networks are chaotic, featuring complex branching patterns and lack of hierarchy (Gillies, 1999; Konerding, 1999; Less, 1991). Vessel diameters are irregular and lengths between branching points are often very long. The result is a high geometrical resistance to blood flow, that such as small decreases in perfusion pressure, which have little effect in normal tissues, can be catastrophic in tumours (Sevick and Jain, 1989). Capillary blood contains abnormally high levels of deoxygenated blood (Mueller-Klieser, 1981), which, combined with heterogeneous blood flow and large intercapillary distances, contributes to micro-regional hypoxia in tumours (Vaupel and Hockel, 2000). The tumour is also starved of nutrient, under acidic conditions (owing to lactate production from anaerobic glycolysis) and under oxidative stress (Brown and Bicknell, 2001; Toyokuni, 1995). In this environment, endothelial cells are strikingly different from those in a normal tissue. Differently from the quiescent health endothelium, the endothelium in tumours proliferates rapidly and contributes to active angiogenesis (Denekamp and Hobson, 1982). Moreover, the development of new vascular networks depends on tumour and surrounding cells that are in constant communication with the tumour microenvironment: a complicated unorganized tissue of various cell types, such as fibroblasts, pericytes, mesenchymal and hematopoietic cells, endothelial cells, immune cells and extracellular matrix molecules (Shojaei and Ferrara, 2008).

All these differences in the architecture and in the cellular and biochemical composition between normal and tumour blood vessels provide the rationale for specific antivascular therapies in cancer.

The pivotal role of tumour vasculature and the effects of its selective destruction were already highlighted in 1923, when Woglom suggested that a damage of the capillary system might be the most effective way to inhibit tumour growth (Woglom, 1923).

Abbreviations used in this paper: NB, Neuroblastoma; VDA, vascular disrupting agent.

*Address correspondence to: Mirco Ponzoni or Fabio Pastorino. ExperimentalTherapies Unit, Laboratory of Oncology, G. Gaslini Children's Hospital, 16148-Genoa, Italy.Tel: +39-010-5636342. Fax: +39-010-3779820. e-mail: mircoponzoni@ ospedale-gaslini.ge.it or fabiopastorino@ ospedale-gaslini.ge.it

\#These Authors share the last co-authorship.

Final, author-corrected PDF published online: 27 July 2011.

ISSN: Online 1696-3547, Print 0214-6282

(C) 2011 UBC Press

Printed in Spain 
Subsequently, in 1971 Folkman proposed that tumour growth and metastasis were angiogenesis dependent (Folkman, 1971) and in the early 1980s Denekamp described the concept behind the exploration of therapeutic strategies that could selectively compromise the functions of the tumour blood vessels (Denekamp, 1990; Denekamp, 1993; Denekamp and Hobson, 1982). Since tumour blood vessels are constantly growing to meet the needs of the expanding malignant cell population (Hirst, 1982; Hobson and Denekamp, 1984), she further postulated that some parts of the blood vessel network that supplies the tumour will be newly formed and immature. Typically the vasculature of normal, healthy adult tissues is extremely stable (Bicknell and Harris, 1992; Eberhard, 2000), thus the neo-formation of the vasculature within the tumour should be highly exploitable. In fact, current investigations towards the development of agents that target tumour vascularization aim to exploit this 'Achille's heel' of the tumour blood vessel network. Rapid efforts in recent years have now resulted in the identification of a variety of potential targets and a large number of investigational drugs and agents capable of targeting tumour blood vessels have been actively pursued (Arap, 1998; Ellis, 2001; Kerbel, 2000; Pastorino, 2007; Ruoslahti, 2002; Siemann and Horsman, 2009). The application of vascular targeting strategies as adjuvant to standard therapeutic modalities may offer unique opportunities to develop even more effective cancer therapies. Moreover, rather than targeting the neoplastic cell population directly, this treatment strategy involves the impairment of the nutritional support of the tumour by targeting the tumour blood vessel network.

There are several advantages of using chemotherapeutic agents directed to proliferating endothelial cells in the tumour vasculature rather than directed to tumour cells. Firstly, antivascular therapies may circumvent the major mechanism of intrinsic drug resistance, resulting from high interstitial pressure gradients within tumours (Jain, 1998) and the acquired drug resistance of tumour cells, resulting from genetic and epigenetic mechanisms that reduce the subsequent effectiveness of available drugs (Klement, 2000). Secondly, the fact that a large number of cancer cells depend upon a small number of endothelial cells for their growth and survival, therapies against the tumour endothelium might also amplify their therapeutic effects (Jain, 2001). Finally, the therapeutic targets are partially independent of the type of solid tumour; killing of proliferating endothelial cells in the tumour microenvironment can be effective against a large amount of cells in a variety of malignancies.

Vascular targeting therapies fall into two general categories based on whether they interfere with new blood vessel development (angiogenesis inhibitors, Als) or damage the established tumour vasculature (vascular disrupting agents, VDAs) (Bloemendal, 1999; Ellis, 2001; Siemann, 2004b; Thorpe, 2004). Als seek to inhibit the tumour-initiated angiogenic process by interrupting essential aspects of angiogenesis, most notably signalling between the tumour and endothelial and stromal cells, and endothelial cell functions in order to prevent new blood vessel formation (Siemann and Horsman, 2009). Als differ from VDAs not only in their mode of action but also in their therapeutic regimen and in the type and extent of neoplastic diseases that are likely to be susceptible (Siemann, 2005).

The VDAs approach involves instead the application of therapeutics seeking the preferential destruction of the established tumour vessel network. The VDAs selectively target tumour vasculature on the basis of structural and functional abnormalities of these vessels (Chaplin and Dougherty, 1999; Denekamp, 1990; Siemann, 2002) and cause direct damage to the previously established tumour endothelium. This results in a rapid and selective vascular shutdown and in a secondary tumour cell death caused by ischemia, leading to extensive tumour cell necrosis (Chaplin and Dougherty, 1999; Chaplin, 2006; Siemann, 2004a; Siemann and Horsman, 2009; Thorpe, 2004) as a result of oxygen and nutrient deprivation. Moreover, extended vascular shutdown, which is necessary for tumour cell kill, requires a complex series of events involving coagulation and the tumour infiltration by immune effector cells (Tozer, 2008). Thus, vascular targeting agents can result in tumour cell death by indirect means ("starving" the tumour cells of their blood supply) and may, therefore, be effective against tumours, which are resistant to conventional antiproliferative chemotherapy (Burrows and Thorpe, 1994; Denekamp, 1993).

VDAs comprise two main classes: (1) small-molecules, that localize to the tumour endothelium by exploiting the known differences between tumour and normal endothelium to induce selective vascular dysfunction, and (2) ligand-based therapies, including antibodies and peptides that specifically deliver chemotherapeutics, toxins, procoagulant and proapoptotic effectors to the tumour endothelium (Pilat and Lorusso, 2006; Siemann, 2004b; Thorpe, 2004).

Two prototype of small-molecule VDAs are represented by: tubulin-depolymerizing agents and flavonoids. Tubulin-depolymerizing agents act by disorganising the microtubules within tumour endothelial cells. Specifically, they bind to the 9-tubulin sub-units preventing the formation of microtubules (Grosios, 1999; Kanthou and Tozer, 2002; Tozer, 2001). These drugs, including Combrestatin A-4P (CA4P), ZD6126, AVE8062, NPI2358, MN029, and OXi4503 (Chaplin, 2006; Siemann, 2004b), selectively disrupt the cytoskeleton of proliferating tumour endothelial cells (Galbraith, 2001) and block vascular endothelial-cadherin signaling (Vincent, 2005), resulting in endothelial cell-shape changes and detachment, ultimately leading to vascular collapse and induction of widespread tumour necrosis. On the other hand, the main effect of flavonoids on endothelial cells is believed to involve the induction of cytokines, especially TNF- $\alpha$, leading to the induction of extensive hemorrhagic necrosis in tumours as a result of vascular collapse (Baguley and Ching, 2002).

Both the tubulin-depolymerizing small-molecule drugs and the flavonoids have been shown to have potent antivascular and antitumour efficacy in a wide variety of preclinical models, indeed the lead agents are undergoing clinical evaluation (Chaplin, 2006).

Ligand-based VDAs use a targeting ligand to achieve selectivity of binding to and occluding tumour vasculature. The tumour vasculature may represent an ideal target for ligand-based treatments, because the accessibility of the endothelium significantly attenuates the delivery problems that typically are associated with such strategies (Siemann, 2004b).

The ligand-based therapies include (1) biological response modifiers or cytokines, such as tumour necrosis factor (TNF) (Corti and Ponzoni, 2004), (2) certain chemotherapeutic drugs, such as vinka alkaloids and arsenic trioxide (Griffin, 2005; Pasquier, 2007), and (3) a variety of strategies that use either antibodies, peptides, or growth factors for binding selectively to tumour vessels (Chaplin, 2006; Pastorino, 2006; Pero, 1999; Siemann, 2004a; Siemann, 2004b; Thorpe, 2004). Moreover, different approaches based on linking antibodies or peptides recognizing tumour-associated 
vasculature, to toxins, pro-coagulant, and pro-apoptotic effector molecules to induce endothelial cell damage have also been explored (Siemann, 2004b; Thorpe, 2004). One of the more promising approach reported for vascular targeting is the coupling of specific ligands, such as antibodies and peptides, to the external surface of liposomes encapsulating chemotherapeutic agents (Allen, 2002; Allen and Cullis, 2004; Pastorino, 2007).

Antigenic determinants selectively and constitutively expressed on or near the tumour neovasculature are of particular interest. Some of these determinants, including endoglin (Burrows, 1995; Seon, 2002), vascular endothelial growth factor (VEGF) receptors (Brekken and Thorpe, 2001; Veenendaal, 2002), $\alpha_{v} \beta_{3}$-integrins (Arap, 1998; Brooks, 1994), the fibronectin EDB domain (Nilsson, 2001), the prostate-specific membrane antigen (Chang, 1999) and specific aminopeptidases (Arap, 1998; Marchio, 2004; Taylor, 1993) have been identified as targets for ligand-directed approaches involving VDAs. Preclinical investigations employing such liganddirected VDAs have shown not only the homing of the therapeutic moieties to tumour vessels but also the selective destruction of tumour vasculature (Pastorino, 2003a; Thorpe, 2004).

\section{The orthotopic animal model}

In the development of new and more effective antivascular agents, it is of notable importance to have model systems available that can mimic the tumour biology observed in patients and give accurate information about signalling networks involved in vascular maintenance.

The study of these clinically relevant parameters required the tumour populations to be placed in the appropriate organ environment, either as orthotopic primary tumour cell inoculum (with subsequent spontaneous metastasis) or as experimental metastasis into relevant organs after intravenously tumour cell injection. Studies have established that the expression of cellular properties required for acquiring both the primary and the metastatic (the ability to metastatize to and colonize the distant organs) phenotypes, are dependent on both intrinsic properties of the tumour cells and host factors, which can differ between tissues and organs (Talmadge, 2007).

Animal models, by definition, are an approximation of reality, and their use for studying and developing antivascular therapies is controversial (Talmadge, 2007).

Fidler (Fidler, 1990), demonstrated that the microenvironment of subcutaneously injected human tumours is radically different from the original milieu and therefore, despite of species differences, the corresponding mouse organ of tumour origin should more closely resemble the original microenvironment than the subcutaneous milieu. Although subcutaneous sites are easily accessible and allow rapid screening of new antitumour compounds, increasing evidence demonstrates that faithful reproduction of the tumour microenvironment and more predictive treatment responses occur with orthotopic tumour implantation, in which either tumour cells or tumour fragments (surgical orthotopic implantation) are implanted within the organ corresponding to the original human tumour site (Fidler, 1991; Hoffman, 1999; Killion, 1998).

To date, a large body of published studies on orthotopic systems suggest that the results are likely to better reflect the behaviour and the molecular features of tumour in patients. Orthotopic implantation allows rapid growth of local tumour and spreading of distant metastases and seems to recapitulate the morphology and the growth characteristics of clinical disease (Fidler, 1986; Fidler, 1991; Hoffman, 1999). Indeed, clinical observation have suggested that the organ environment can influence the response of tumour to chemotherapies (Fidler, 2002; Killion, 1998) and orthotopic models allow to obtain a vasculature network similar to that of patient being useful for antivascular drug discovery. Interestingly, the vasculature of the tumour tends to acquire characteristics similar to those of the host environment (Langenkamp and Molema, 2009). The neovasculature of a specific tumour type can be indeed drastically different in terms of vascular architecture, microvascular density (MVD), permeability, vessel distribution, and gene expression, when the same tumour is grown in different locations of the body (Langenkamp and Molema, 2009). For example, the microvasculature of human glioblastoma implanted subcutaneously in nude mice became extensively fenestrated, with a large population of caveolae and a relatively high permeability, similar to the host endothelium of the subcutaneous space (Roberts, 1998). In contrast, the same tumour implanted in the brain acquired a microvasculature that is considerably less fenestrated, resembling more closely the brain microvascular phenotype. Similarly, human renal carcinoma cells implanted orthotopically into the kidney of nude mice became highly vascularized, whereas the subcutaneously growing of the same tumour did not (Singh, 1994), and the vasculature of melanoma growing intracranially had an higher density, but a smaller diameter, than the vasculature found in subcutaneously growing tumours (Kashiwagi, 2005). Differential patterns of expression of angiogenic genes accompany, and are probably responsible for these host environment-induced differences in vascularization. Renal cell carcinoma growth in the kidney resulted in a higher expression of fibroblast growth factor-2 (FGF-2), compared with the same tumour growing subcutaneously (Singh, 1994). Likewise, the decrease in fenestration pattern and permeability in glioblastoma tumours growing in the brain, compared with those growing subcutaneously, was accompanied by an elevated expression of the receptors for VEGF, whereas expression of VEGF itself did not differ per tumour location (Roberts, 1998). Human ductal pancreatic adenocarcinoma grown in the pancreas of nude mice exhibited enhanced expression of VEGF with concomitant higher growth rate compared with subcutaneous tumours implanted in the abdominal wall (Tsuzuki, 2001). Colon cancer xenografts in their orthotopic location produced higher levels of interleukin-8, carcinoembryonic antigen, as well as multidrug resistance proteins, than their subcutaneously growing counterparts (Kitadai, 1995). In addition to influence angiogenic genes expression, the host microenvironment can also determine the functionality of genes. Number, nature, and level of active angiogenic genes in a tumour could determine the capacity to overrule the host-environment driven control of tumour vascular behaviour that is intricately controlled by the microenvironment, as elegantly demonstrated by Kwei and colleagues (Kwei, 2004).

All these data emphasize the importance of the tumour microenvironment and the active reciprocal communication between tumour cells and the microenvironment. This explains the need for appropriate preclinical animal models representing the clinical setting in which to evaluate novel antivascular therapies for cancer in the context of the specific tumour environment. In this regard, data from orthotopic tumour systems may give a better indication of the potential clinical activity of antivascular drugs. 
In summary, the orthotopic implantation of tumour cells into mice is mandatory. The importance of the orthotopic environment for reproducing human tumour conditions has been indeed shown for colon (Thalheimer, 2006), renal (Naito, 1987), breast (Price, 1990), bladder (Dinney, 1995), prostate (Stephenson, 1992), pancreatic (Bruns, 1999), lung (Boehle, 2000), esophageal (Gros, 2009) carcinomas and in neuroectoderma-derived tumours, such as melanoma and neuroblastoma (Pastorino, 2003a; Pastorino, 2007).

\section{Targeting the tumour vasculature in vivo}

Here, we present an overview of some vascular-targeting studies performed in orthotopic animal models.

As mentioned above, small molecules VDAs act on pathophysiological differences between tumour and normal tissue endothelium to achieve selective occlusion of tumour vessels. Among these agents, the combretastatin A-4 (CA-4) is one of the most promising (Lin, 1988).

The anti-tumour effects of combretastatin A-4 and its prodrug, the more soluble sodiumphosphate salt (CA-4P) has been evaluated in orthotopic models of human colon adenocarcinoma (Grosios, 1999) in which tumour growth in the colon is often accompanied by formation of metastasis in other parts of the body (Cowen, 1995). The primary tumour as well as some of the metastatic deposits (including body wall, lymph nodes and kidney deposits) developed extensive vasculature, underlining the importance of using orthotopic model in antivascular therapeutic studies. Extensive haemorrhagic necrosis after treatments was observed in vascularized but not in avascular tumours in mice both at the primary and metastatic sites. This observation is the clearest evidence that a direct effect of these compounds on tumour vasculature is essential for anti-tumour activity in vivo.

The effect of CA-4 was also evaluated in combination with Oxi4503, the diphosphate prodrug of CA1P (Pettit, 1989) in an orthotopically transplanted human renal cell carcinoma xenograft model, by the vascular casting and the chord-length distribution techniques (Salmon, 2006a; Salmon, 2006b). The results illustrated the loss of tumour vasculature and induction of wide scale necrosis in the central regions of the tumour. Compared to the surrounding normal tissue a lower vascular density at the tumour periphery after treatment with either agent was seen, suggesting that
A

\section{Orthotopic neuroblastoma model: injection in the adrenal gland}
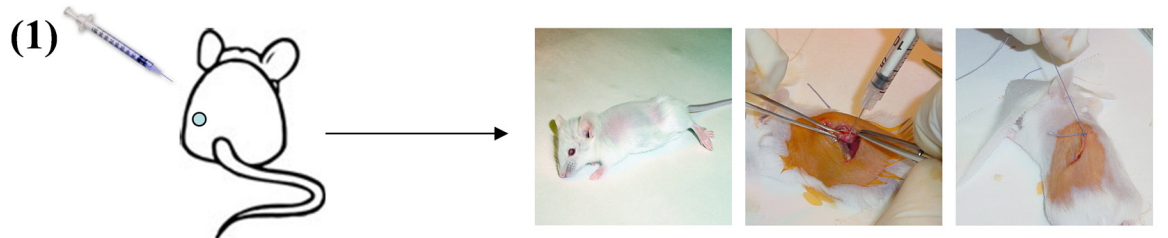

(2)

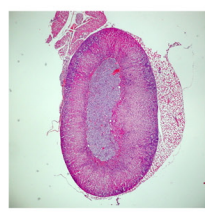

Normal adrenal gland

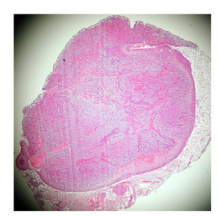

NB growing in the adrenal gland $\left(\mathrm{T}_{14}\right)$
+ metastastatic spreading (liver, spleen, ovary, lung, kidney), $\mathrm{T}_{21-35}$

\section{B Tumour growth inhibition by TVT-DOX}

(1)

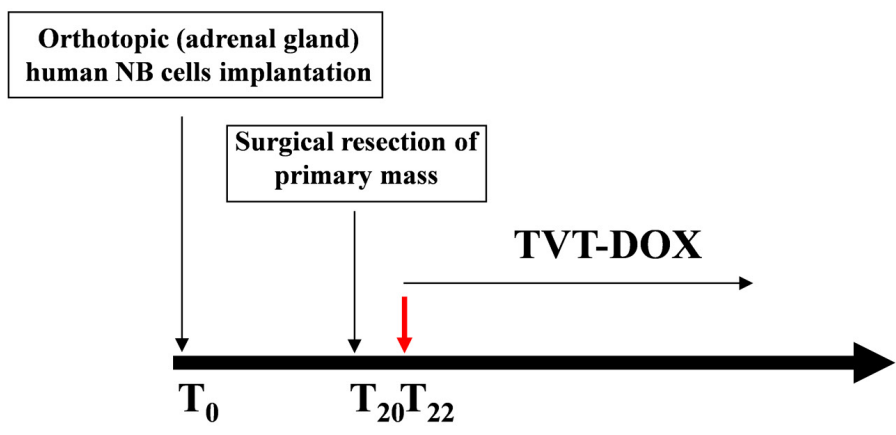

(2)

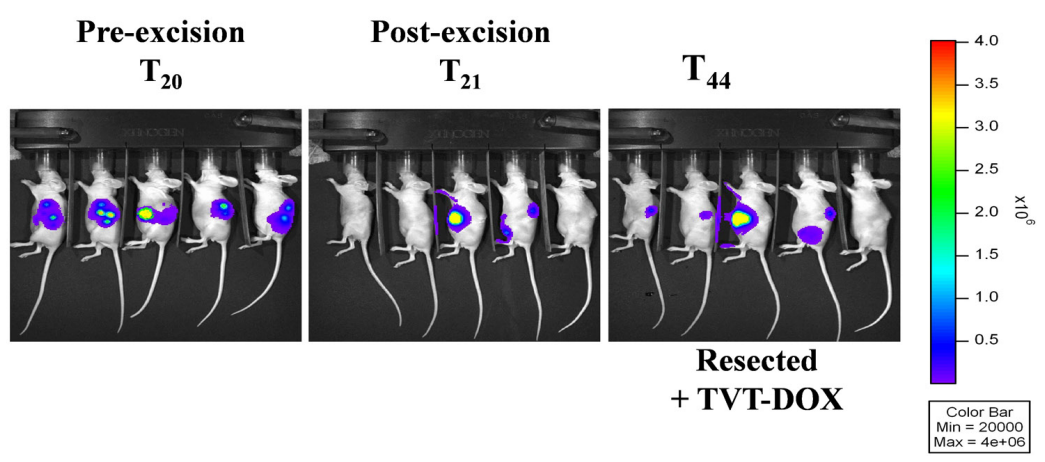

Fig. 1. Orthotopic implantation, expansion and evaluation. (A) NB orthotopic implantation procedure. (1) After anaesthesia, mice are injected with NB cell lines, after laparatomy, in the left adrenal gland. (2) Comparison, by histological analysis, between normal and NB-injected adrenal glands 14 days after tumour challenge. The establishment of metastasis is observed in several organs from 21 to 35 days after cell injection. (B) Evaluation of NB tumour growth inhibition by BLI (1) Luciferase-transfected NB tumour cells are orthotopically implanted in mice on day 0 and had their tumours surgically resected on day 20. TVT-DOX treatment started at day 22. (2) Orthotopic expansion, achieved tumour resection, and response to TVT-DOX are visualized via a highly sensitive, cooled CCD camera mounted in a light-tight specimen box (IVIS; Xenogen). Animals are injected intraperitoneally with the substrate D-luciferin and are anesthetized with $1 \%$ to $3 \%$ isoflurane and placed onto a warmed stage inside a light-tight camera box, with continuous exposure to $1 \%$ to $2 \%$ isoflurane. Imaging times ranged from $1 \mathrm{~s}$ to 3 min depending on the tumour model and the desired time point. The level of bioluminescence is recorded as photons per second. 
invading tumour cells increase the inter-vascular spacing between normal blood vessels located within this region.

Ligand-targeted VDAs bind selectively to components of tumour blood vessels, carrying the coupled agents to occlude the vessels. Therefore, ligand-directed VDAs are composed of targeting and effector moieties linked together, usually via chemical cross-linkers or peptide bonds (Thorpe, 2004). The targeting moiety is usually an antibody or a peptide directed against markers selectively upregulated on tumour endothelial cells (Thorpe, 2004).

On this regard, a successful strategy was based on the use of monoclonal antibodies to phosphatidylserine (PS) (Ran, 2002). It has been found that PS exposure on vascular endothelial cells is induced by hypoxia/reoxygenation, acidity, as well as by the presence of thrombin, inflammatory cytokines, and reactive oxygen species. This suggests that stress conditions in the tumour microenvironment may be responsible for inducing PS exposure on viable endothelium (Ran and Thorpe, 2002). In 2005, Thorpe PE et al., (Ran, 2005) tested the use of PS as a potential drug target for breast cancer. By the identification of an immunoglobulin $G$ monoclonal antibody, 3G4, that binds to phosphatidylserine, they evaluated its effect within orthotopic breast tumour models in SCID mice. A specific homing to tumour blood vessels and a selective vascular damage with reduction of tumour vascularity and plasma volume, as well as a delay in tumour growth and the development of necrosis were obtained.

Several techniques are been using to find novel markers that could aid the development of targeting moieties with increased tumour specificity over those currently available. One of the most promising technique is the in vivo phage display library screening, in which vast numbers of phages, each expressing a different peptide, are injected into animals (Trepel, 2002) or terminally ill patients (Arap, 2002). A short time later, samples of tumour and normal tissues (used as control) are removed and phages that have localized into both tumour cells and tumour vasculature are recovered. Phage-contained peptides that confer specific binding are then identified (Trepel, 2002).

In vivo phage display-based studies allowed to identify several peptides such as the peptide containing the sequence RGD, an $\alpha_{v} \beta_{3} / \alpha_{v} \beta_{5}$ binding motif, that can bind to the tumour (neo)vasculature (Arap, 1998; Pasqualini, 1997). Moreover, systemic administration of phages into nude mice led to the selection of a novel tumour vasculature-homing phage carrying the sequence NGR (Arap, 1998), able to recognize the tumour isoform of aminopeptidase $\mathrm{N}$ (APN, CD13). Constitutively, APN is a membrane-bound metallopeptidase that plays multiple functions as a regulator of various hormones and cytokines, protein degradation, antigen presentation, cell proliferation, cell migration, and angiogenesis (Luan and Xu, 2007; Razak and Newland, 1992; Riemann, 1999). More recently, this technique allows the identification of the sequence CPRECES, specific for another aminopeptidase, the aminopeptidase A (APA), expressed on endothelial and perivascular tumour cells (Marchio, 2004).

Various compounds, including cytotoxic drugs, cytokines, antiangiogenic agents, viral particles, fluorescent and contrast tracers, DNA complexes, and other biologic response modifiers have been coupled or synthetically added to NGR peptides in order to increase their vasculature-homing effects (Arap, 1998; Buehler, 2006; Corti and Ponzoni, 2004; Curnis, 2005; Curnis, 2000; Grifman, 2001; Pastorino, 2006; Pastorino, 2003a; Zarovni, 2004).
Recently, we showed that liposomes are attractive for targeting drugs and other effectors to tumour vasculature because they can carry large payloads. Using nanoparticles of doxorubicin (DOX) targeted to tumour endothelial cells by coupling the liposomes with peptides containing the NGR sequence, we evaluated their efficacy in orthotopic model of human neuroblastoma (Pastorino, 2003a). Specifically, mice were orthotopically injected in the capsule of the left adrenal gland and tumour growth was evaluated by histological analysis, as shown in Fig. 1A. NGR-targeted, doxorubicin-encapsulated, liposomes caused endothelial and tumour cells apoptosis, and showed antitumour and antimetastatic activity in neuroblastoma (Pastorino, 2003a). In a subsequent study, we evaluated the efficacy of clinical-grade formulation of NGR-peptide-targeted liposomal doxorubicin, TVT-DOX, in several murine orthotopic xenografts of doxorubicin resistant human cancer, including lung, ovarian, and neuroblastoma (Pastorino, 2008). In addition, in order to assess the effect of NGR-targeted liposomal DOX therapy in controlling minimal residual disease (MRD) and in helping to prevent tumour relapse, a new neuroblastoma model was set up to take advantage of new imaging techniques. In vivo bioluminescence imaging (BLI) is indeed a non-invasive assay for the detection of small numbers of cells, and it enables the quantification of tumour growth within internal organs (Edinger, 2003). Using a highly sensitive, cooled CCD camera mounted in a light-tight specimen box, the initial trafficking of the malignant cells through the body, and organspecific homing and orthotopic expansion over time were readily visualized and quantified. We used a reporter gene that code for a bioluminescent marker to permanently label NB cell lines, and we monitored primary tumours and metastases growth following orthotopic implantation into mice. Fig. 1B shows resection of primary tumour and response to treatment with TVT-DOX. Treatment with TVT-DOX induced a partial arrest in primary tumour growth and an inhibition of MRD in treated mice. Moreover, TVT-DOX resulted in effectively killing angiogenic tumour blood vessels and, indirectly, the tumour cells that these vessels supported (Pastorino, 2008).

On the basis of the "marker heterogeneity" concept, pointed out by Kerbel et al., (Kerbel, 2001), tumours can modulate the markers they induce on the adjacent endothelia, giving rise to heterogeneity in the expression of tumour vessel markers. Thus, it has been assumed that the use of combinations of VDAs that recognize two, or more, differently regulated, tumour vessel markers could enhance the therapeutic effects.

Adual vascular targeting efficacy was evaluated in orthotopicallyimplanted tumour animal models by targeting both the endothelial cells (using a vascular endothelial growth factor receptor inhibitor, AEE788) and the pericytes (using STI571) (Lu, 2007). The combination therapy showed a significantly decrease in pericyte coverage with reduction of microvessel density and an enhanced endothelial cell apoptosis.

With the similar purpose, we examined neuroblastoma orthotopic tumours for the therapeutic efficacy of a novel, APA-targeted, liposomal formulation of DXR, alone and in combination with APN-targeted DXR-loaded liposomes. Results obtained from these experiments showed that the use of APA- and APN-targeted, DXR-entrapped, liposomes administered in combination, led to a significant increase in life span compared to each treatment administered separately, obtaining a strong enhanced anti-tumour effect and induction of endothelial cells apoptosis and decrease in pericyte coverage (Loi 2010). 


\section{Combination therapy involving vascular disrupting agents (VDAs)}

VDAs selectively destroy the central region of tumours leaving a peripheral rim of survival tumour cells. This pattern of tumour cell killing is characteristic of vascular targeting agents (Thorpe, 2004; Thorpe, 2003).

It is thought that vascular targeting agents are most effective against vessels in the interior of the tumour because of the high interstitial pressure in these regions and the vascular architecture. Interstitial fluid pressure rises precipitously from the tumour periphery to the tumour centre (Boucher, 1990), such that an increase in vascular permeability at the tumour centre following treatment might be catastrophic, whereas it is tolerated at the periphery (Tozer, 2005). Small-calibre vessels are also more sensitive to shutdown than larger ones and the proportion of these is often far higher at the centre than at the periphery (Tozer, 1999). There is often a complex vascular plexus at the tumour periphery, compared with a much lower vascular density at the centre, so that in the event of extensive vascular damage, residual flow is likely to persist at the periphery rather than at the centre. For these reasons, cells in this rim of viable tumour tissue are likely to be highly proliferative and well nourished. These characteristics, coupled with the accessibility of the surviving tumour cells to systemically administered agents, make these cells susceptible to killing by conventional methods. Conversely, VDAs induce the destruction of large areas of the tumour interior and exhibit excellent activity against bulky disease (Landuyt, 2001; Siemann and Shi, 2003), which is typically resistant to conventional anticancer treatment.

Thus, combining VDAs with cytotoxic chemotherapy, radiation and antiangiogenic treatments would be expected to lead to additive or even synergistic antitumour activity.

This concept has been extensively tested in preclinical settings by using a variety of tumour models and small-molecule targeting agents. To date, combined-modality approaches involving VDAs have included antiangiogenic agents, chemotherapeutic agents, hyperthermia, and radiation (Siemann, 2002; Thorpe, 2004).

Since both the initiation of new vessel formation and the integrity of the existing blood vessel network are critical to the growth and survival of a tumour, such a double assault on the tumour vasculature would appear to be a highly logical approach. The targeting of the tumour vasculature with Als and VDAs is indeed complementary and not redundant. Whereas the VDAs significantly reduced the viable tumour mass, the Als impaired subsequent tumour regrowth by interfering with the re-establishment of the tumour blood vessel network.

The combination of two different targeting strategies was also investigated. Effect of the combination therapy was investigated using the monoclonal antibody $3 G 4$, direct to PS, and chemotherapeutic agents, such as gemcitabine and docetaxel, in pancreatic and breast orthotopic models, respectively (Beck, 2006; Huang, 2005).

The effect of the combination of gemcitabine with $3 G 4$ was significantly better than either therapy alone, suggesting that gemcitabine enhances $3 G 4$ function, or viceversa (Beck, 2006). Similarly, Huang et al., reported that $3 G 4$ enhanced the inhibitory effect of docetaxel on the growth of orthotopically-implanted breast tumour model, pointing out the conditions in the tumour microenvironment play an important role in docetaxel-induced exposure of anionic phospholipids on tumour vascular endothelium (Huang, 2005).
Recently, the murine anti-PS antibody, 2aG4, in combination with local irradiation, was used to treat established gliomas growing in the brains of syngeneic rats that exerts biological characteristics resembling those of human glioblastoma $(\mathrm{He}, 2009)$. It has been shown that 2aG4 treatment not only has an antivascular action when combined with irradiation in this model, but also enhances the immunogenicity of the tumour leading to immunologic control of residual tumour cells. Moreover, antivascular effects and antitumour effects were accompanied by the recruitment of host immune cells in tumour vasculature and the subsequent infiltration into the tumour interstitium, as shown also by other studies (Beck, 2006; Tozer, 2008).

To this regard, we evaluated a successful combination strategy in neuroblastoma model using liposomal formulations of DXR targeted against both tumour cells, via anti-GD, monoclonal antibodies, and against the tumour vasculature, via the NGR peptide (Pastorino, 2006). The anti-GD -targeted liposomes resulted in direct cell kill, including cytotoxicity against cells that were at the tumour periphery and were independent of the tumour vasculature, whereas NGR peptide-targeted liposomal doxorubicin bind to and killed angiogenic blood vessels and, indirectly, the tumour cells that these vessels supported, mainly in the tumour core. The results clearly showed that liposomes administered in a sequential manner were statistically more effective in inhibiting neuroblastoma tumour proliferation in mice compared with formulations given alone (Pastorino, 2003a; Pastorino, 2003b). In conclusion, our novel approach relies on the combination of two different targeting strategies: NGR peptide-targeted liposomal doxorubicin binds to and kills angiogenic blood vessels and, indirectly, the tumour cells that these vessels support; the anti-GD ${ }_{2}$-targeted liposomes result in direct cell kill, including cytotoxicity against cells that are at the tumour periphery and are independent of the tumour vasculature. We believe that this combination approach is a promising one in the search for more effective and less toxic cancer treatments.

\section{Conclusion}

In this review we explained the importance of using the orthotopic implantation of tumour cells in mice models for evaluating the effectiveness of antivascular therapies.

Although the ideal tumour model does not exist, the best approach to select an animal model for testing drug efficacy is to design one that can better reflect the clinical behaviour and can give informations about therapeutic efficacy of therapies. The orthotopic model reproducing the appropriate tumour microenvironment allows the emergence of the biological features of cancer progression, angiogenic process, metastatic phenotype, resistance and therapeutic response to therapies with similar patterns observed in human cancer and, for these reasons, appears appropriate for studying antivascular approaches.

Moreover, what is increasingly obvious is that only an extensive acquisition of experimental in vivo data will ultimately allow adequate interpretation of preclinical studies that can potentially be translated into promising clinical therapeutic regimens.

\section{Acknowledgements}

We thank Ambrilia Biopharma Inc for providing us with TVT-DOX. Work supported by Associazione Italiana Ricerca Cancro (IG and MFAG), Italian Ministry of Health. 


\section{References}

ALLEN, T. M. (2002). Ligand-targeted therapeutics in anticancer therapy. Nat Rev Cancer 2: $750-763$.

ALLEN, T. M., and CULLIS, P. R. (2004). Drug delivery systems: entering the mainstream. Science 303: 1818-1822.

ARAP, W., KOLONIN, M. G., TREPEL, M., LAHDENRANTA, J., CARDO-VILA, M., GIORDANO, R. J., MINTZ, P. J., ARDELT, P. U., YAO, V. J., VIDAL, C. I. et al. (2002). Steps toward mapping the human vasculature by phage display. Nat Med 8: 121-127.

ARAP, W., PASQUALINI, R., and RUOSLAHTI, E. (1998). Cancer treatment by targeted drug delivery to tumor vasculature in a mouse model. Science 279: 377-380.

BAGULEY, B. C., and CHING, L. M. (2002). DMXAA: an antivascular agent with multiple host responses. Int J Radiat Oncol Biol Phys 54: 1503-1511.

BALUK, P., MORIKAWA, S., HASKELL, A., MANCUSO, M., and MCDONALD, D. M. (2003). Abnormalities of basement membrane on blood vessels and endothelial sprouts in tumors. Am J Pathol 163: 1801-1815.

BECK, A. W., LUSTER, T. A., MILLER, A. F., HOLLOWAY, S. E., CONNER, C. R., BARNETT, C. C., THORPE, P. E., FLEMING, J. B., and BREKKEN, R. A. (2006). Combination of a monoclonal anti-phosphatidylserine antibody with gemcitabine strongly inhibits the growth and metastasis of orthotopic pancreatic tumors in mice. Int J Cancer 118: 2639-2643.

BICKNELL, R., and HARRIS, A. L. (1992). Anticancer strategies involving the vasculature: vascular targeting and the inhibition of angiogenesis. Semin Cancer Biol 3: 399-407.

BLOEMENDAL, H. J., LOGTENBERG, T., and VOEST, E. E. (1999). New strategies in anti-vascular cancer therapy. Eur J Clin Invest 29: 802-809.

BOEHLE, A. S., DOHRMANN, P., LEUSCHNER, I., KALTHOFF, H., and HENNEBRUNS, D. (2000). An improved orthotopic xenotransplant procedure for human lung cancer in SCID bg mice. Ann Thorac Surg 69: 1010-1015.

BOUCHER, Y., BAXTER, L. T., and JAIN, R. K. (1990). Interstitial pressure gradients in tissue-isolated and subcutaneous tumors: implications for therapy. Cancer Res 50: 4478-4484.

BREKKEN, R. A., and THORPE, P. E. (2001). Vascular endothelial growth factor and vascular targeting of solid tumors. Anticancer Res 21: 4221-4229.

BROOKS, P. C., CLARK, R. A., and CHERESH, D. A. (1994). Requirement of vascular integrin alpha $v$ beta 3 for angiogenesis. Science 264: 569-571.

BROWN, N. S., and BICKNELL, R. (2001). Hypoxia and oxidative stress in breast cancer. Oxidative stress: its effects on the growth, metastatic potential and response to therapy of breast cancer. Breast Cancer Res 3: 323-327.

BRUNS, C. J., HARBISON, M. T., KUNIYASU, H., EUE, I., and FIDLER, I. J. (1999). In vivo selection and characterization of metastatic variants from human pancreatic adenocarcinoma by using orthotopic implantation in nude mice. Neoplasia 1:50-62.

BUEHLER, A., VAN ZANDVOORT, M. A., STELT, B. J., HACKENG, T. M., SCHRANSSTASSEN, B. H., BENNAGHMOUCH, A., HOFSTRA, L., CLEUTJENS, J. P., DUIJVESTIJN, A., SMEETS, M. B. et al. (2006). cNGR: a novel homing sequence for CD13/APN targeted molecular imaging of murine cardiac angiogenesis in vivo. Arterioscler Thromb Vasc Biol 26: 2681-2687.

BURROWS, F. J., DERBYSHIRE, E. J., TAZZARI, P. L., AMLOT, P., GAZDAR, A. F., KING, S. W., LETARTE, M., VITETTA, E. S., and THORPE, P. E. (1995). Up-regulation of endoglin on vascular endothelial cells in human solid tumors: implications for diagnosis and therapy. Clin Cancer Res 1: 1623-1634.

BURROWS, F. J., and THORPE, P. E. (1994). Vascular targeting--a new approach to the therapy of solid tumors. Pharmacol Ther 64: 155-174.

CHANG, S. S., O'KEEFE, D. S., BACICH, D. J., REUTER, V. E., HESTON, W. D., and GAUDIN, P. B. (1999). Prostate-specific membrane antigen is produced in tumor-associated neovasculature. Clin Cancer Res 5: 2674-2681.

CHAPLIN, D. J., and DOUGHERTY, G. J. (1999). Tumour vasculature as a target for cancer therapy. Br J Cancer 80 Suppl 1: 57-64.

CHAPLIN, D. J., HORSMAN, M. R., and SIEMANN, D. W. (2006). Current development status of small-molecule vascular disrupting agents. Curr Opin Investig Drugs 7: $522-528$

CORTI, A., and PONZONI, M. (2004). Tumor vascular targeting with tumor necrosis factor alpha and chemotherapeutic drugs. Ann N Y Acad Sci 1028: 104-112.

COWEN, S. E., BIBBY, M. C., and DOUBLE, J. A. (1995). Characterisation of the vasculature within a murine adenocarcinoma growing in different sites to evaluate the potential of vascular therapies. Acta Oncol 34: 357-360.

CURNIS, F., GASPARRI, A., SACCHI, A., CATTANEO, A., MAGNI, F., and CORTI, A. (2005). Targeted delivery of IFNgamma to tumor vessels uncouples antitumor from counterregulatory mechanisms. Cancer Res 65: 2906-2913.

CURNIS, F., SACCHI, A., BORGNA, L., MAGNI, F., GASPARRI, A., and CORTI, A (2000). Enhancement of tumor necrosis factor alpha antitumor immunotherapeutic properties by targeted delivery to aminopeptidase N (CD13). Nat Biotechnol 18: 1185-1190.

DENEKAMP, J. (1990). Vascular attack as a therapeutic strategy for cancer. Cancer Metastasis Rev 9: 267-282.

DENEKAMP, J. (1993). Review article: angiogenesis, neovascular proliferation and vascular pathophysiology as targets for cancer therapy. Br J Radiol 66: 181-196.

DENEKAMP, J., and HOBSON, B. (1982). Endothelial-cell proliferation in experimental tumours. Br J Cancer 46: 711-720.

DINNEY, C. P., FISHBECK, R., SINGH, R. K., EVE, B., PATHAK, S., BROWN, N., XIE, B., FAN, D., BUCANA, C. D., FIDLER, I. J., and et al., (1995). Isolation and characterization of metastatic variants from human transitional cell carcinoma passaged by orthotopic implantation in athymic nude mice. JUro/ 154: 1532-1538.

DVORAK, H. F., NAGY, J. A., and DVORAK, A. M. (1991). Structure of solid tumors and their vasculature: implications for therapy with monoclonal antibodies. Cancer Cells 3: 77-85.

DVORAK, H. F., NAGY, J. A., DVORAK, J. T., and DVORAK, A. M. (1988). Identification and characterization of the blood vessels of solid tumors that are leaky to circulating macromolecules. Am J Pathol 133: 95-109.

EBERHARD, A., KAHLERT, S., GOEDE, V., HEMMERLEIN, B., PLATE, K. H., and AUGUSTIN, H. G. (2000). Heterogeneity of angiogenesis and blood vesse maturation in human tumors: implications for antiangiogenic tumor therapies. Cancer Res 60: 1388-1393.

EDINGER, M., CAO, Y. A., VERNERIS, M. R., BACHMANN, M. H., CONTAG, C. H., and NEGRIN, R. S. (2003). Revealing lymphoma growth and the efficacy of immune cell therapies using in vivo bioluminescence imaging. Blood 101:640-648.

ELLIS, L. M., LIU, W., AHMAD, S. A., FAN, F., JUNG, Y. D., SHAHEEN, R. M., and REINMUTH, N. (2001). Overview of angiogenesis: Biologic implications for antiangiogenic therapy. Semin Oncol 28: 94-104

FIDLER, I. J. (1986). Rationale and methods for the use of nude mice to study the biology and therapy of human cancer metastasis. CancerMetastasis Rev 5:29-49.

FIDLER, I. J. (1990). Critical factors in the biology of human cancer metastasis: twenty-eighth G.H.A. Clowes memorial award lecture. CancerRes 50:6130-6138.

FIDLER, I. J. (1991). Orthotopic implantation of human colon carcinomas into nude mice provides a valuable model for the biology and therapy of metastasis. Cancer Metastasis Rev 10: 229-243.

FIDLER, I. J. (2002). The organ microenvironment and cancer metastasis. Differentiation 70: 498-505.

FOLKMAN, J. (1971). Tumor angiogenesis: therapeutic implications. N Engl J Med 285: 1182-1186.

GALBRAITH, S. M., CHAPLIN, D. J., LEE, F., STRATFORD, M. R., LOCKE, R. J., VOJNOVIC, B., and TOZER, G. M. (2001). Effects of combretastatin A4 phosphate on endothelial cell morphology in vitroand relationship to tumour vascular targeting activity in vivo. Anticancer Res 21: 93-102.

GILLIES, R. J., SCHORNACK, P. A., SECOMB, T. W., and RAGHUNAND, N. (1999). Causes and effects of heterogeneous perfusion in tumors. Neoplasia 1: 197-207.

GRIFFIN, R. J., WILLIAMS, B. W., PARK, H. J., and SONG, C. W. (2005). Preferential action of arsenic trioxide in solid-tumor microenvironment enhances radiation therapy. Int J Radiat Oncol Biol Phys 61: 1516-1522.

GRIFMAN, M., TREPEL, M., SPEECE, P., GILBERT, L. B., ARAP, W., PASQUALINI, R., and WEITZMAN, M. D. (2001). Incorporation of tumor-targeting peptides into recombinant adeno-associated virus capsids. Mol Ther 3: 964-975.

GROS, S. J., DOHRMANN, T., PELDSCHUS, K., SCHURR, P. G., KAIFI, J. T., KALININA, T., REICHELT, U., MANN, O., STRATE, T. G., ADAM, G., HOFFMAN, R. M., and IZBICKI, J. R. (2010). Complementary use of fluorescence and magnetic resonance imaging of metastatic esophageal cancer in a novel orthotopic mouse model. Int J Cancer 126: 2671-2681.

GROSIOS, K., HOLWELL, S. E., MCGOWN, A. T., PETTIT, G. R., and BIBBY, M. C. (1999). In vivo and in vitro evaluation of combretastatin A-4 and its sodium 
phosphate prodrug. Br J Cancer 81: 1318-1327

HANAHAN, D., and FOLKMAN, J. (1996). Patterns and emerging mechanisms of the angiogenic switch during tumorigenesis. Cell 86: 353-364.

HASHIZUME, H., BALUK, P., MORIKAWA, S., MCLEAN, J. W., THURSTON, G., ROBERGE, S., JAIN, R. K., and MCDONALD, D. M. (2000). Openings between defective endothelial cells explain tumor vessel leakiness. Am J Pathol 156: 1363-1380.

HE, J., YIN, Y., LUSTER, T. A., WATKINS, L., and THORPE, P. E. (2009). Antiphosphatidylserine antibody combined with irradiation damages tumor blood vessels and induces tumor immunity in a rat model of glioblastoma. Clin Cancer Res 15: 6871-6880.

HIRST, D. G., DENEKAMP, J., and HOBSON, B. (1982). Proliferation kinetics of endothelial and tumour cells in three mouse mammary carcinomas. Cell Tissue Kinet 15: 251-261.

HOBSON, B., and DENEKAMP, J. (1984). Endothelial proliferation in tumours and normal tissues: continuous labelling studies. Br J Cancer 49: 405-413.

HOFFMAN, R. M. (1999). Orthotopic metastatic mouse models for anticancer drug discovery and evaluation: a bridge to the clinic. Invest New Drugs 17: 343-359.

HUANG, X., BENNETT, M., and THORPE, P. E. (2005). A monoclonal antibody that binds anionic phospholipids on tumor blood vessels enhances the antitumor effect of docetaxel on human breast tumors in mice. Cancer Res 65: 4408-4416.

JAIN, R. K. (1987). Transport of molecules across tumor vasculature. Cancer Metastasis Rev 6: 559-593.

JAIN, R. K. (1998). The next frontier of molecular medicine: delivery of therapeutics. Nat Med 4: 655-657.

JAIN, R. K. (2001). Normalizing tumor vasculature with anti-angiogenic therapy: a new paradigm for combination therapy. Nat Med 7: 987-989.

KANTHOU, C., and TOZER, G. M. (2002). The tumor vascular targeting agent combretastatin A-4-phosphate induces reorganization of the actin cytoskeleton and early membrane blebbing in human endothelial cells. Blood 99: 2060-2069.

KASHIWAGI, S., IZUMI, Y., GOHONGI, T., DEMOU, Z. N., XU, L., HUANG, P. L., BUERK, D. G., MUNN, L. L., JAIN, R. K., and FUKUMURA, D. (2005). NO mediates mural cell recruitment and vessel morphogenesis in murine melanomas and tissue-engineered blood vessels. J Clin Invest 115: 1816-1827.

KERBEL, R. S. (2000). Tumor angiogenesis: past, present and the near future. Carcinogenesis 21: 505-515.

KERBEL, R. S., YU, J., TRAN, J., MAN, S., VILORIA-PETIT, A., KLEMENT, G., COOMBER, B. L., and RAK, J. (2001). Possible mechanisms of acquired resistance to anti-angiogenic drugs: implications for the use of combination therapy approaches. Cancer Metastasis Rev 20: 79-86.

KILLION, J. J., RADINSKY, R., and FIDLER, I. J. (1998). Orthotopic models are necessary to predict therapy of transplantable tumors in mice. Cancer Metastasis Rev 17: 279-284.

KITADAI, Y., BUCANA, C. D., ELLIS, L. M., ANZAI, H., TAHARA, E., and FIDLER, I. J. (1995). In situ mRNA hybridization technique for analysis of metastasis-related genes in human colon carcinoma cells. Am J Pathol 147: 1238-1247.

KLEMENT, G., BARUCHEL, S., RAK, J., MAN, S., CLARK, K., HICKLIN, D. J., BOHLEN, P., and KERBEL, R. S. (2000). Continuous low-dose therapy with vinblastine and VEGF receptor-2 antibody induces sustained tumor regression without overt toxicity. J Clin Invest 105, R15-24.

KOBAYASHI, H., TSURUCHI, N., SUGIHARA, K., KAKU, T., SAITO, T., KAMURA, T., TSUKAMOTO, N., NAKANO, H., and TANIGUCHI, S. (1993). Expression of alpha-smooth muscle actin in benign or malignant ovarian tumors. Gynecol Oncol 48: 308-313.

KONERDING, M. A., FAIT, E., and GAUMANN, A. (2001). 3D microvascular architecture of pre-cancerous lesions and invasive carcinomas of the colon. $\mathrm{Br} \mathrm{J}$ Cancer 84: 1354-1362.

KONERDING, M. A., MALKUSCH, W., KLAPTHOR, B., VAN ACKERN, C., FAIT, E., HILL, S. A., PARKINS, C., CHAPLIN, D. J., PRESTA, M., and DENEKAMP, J. (1999). Evidence for characteristic vascular patterns in solid tumours: quantitative studies using corrosion casts. Br J Cancer 80: 724-732.

KWEI, S., STAVRAKIS, G., TAKAHAS, M., TAYLOR, G., FOLKMAN, M. J., GIMBRONE, M. A., JR., and GARCIA-CARDENA, G. (2004). Early adaptive responses of the vascular wall during venous arterialization in mice. Am J Pathol 164: 81-89.

LANDUYT, W., AHMED, B., NUYTS, S., THEYS, J., OP DE BEECK, M., RIJNDERS,
A., ANNE, J., VAN OOSTEROM, A., VAN DEN BOGAERT, W., and LAMBIN, P. (2001). In vivo antitumor effect of vascular targeting combined with either ionizing radiation or anti-angiogenesis treatment. Int J Radiat Oncol Biol Phys 49: 443-450.

LANGENKAMP, E., and MOLEMA, G. (2009). Microvascular endothelial cell heterogeneity: general concepts and pharmacological consequences for anti-angiogenic therapy of cancer. Cell Tissue Res 335: 205-222.

LESS, J. R., SKALAK, T. C., SEVICK, E. M., and JAIN, R. K. (1991). Microvascular architecture in a mammary carcinoma: branching patterns and vessel dimensions. Cancer Res 51: 265-273.

LIN, C. M., SINGH, S. B., CHU, P. S., DEMPCY, R. O., SCHMIDT, J. M., PETTIT, G. R., and HAMEL, E. (1988). Interactions of tubulin with potent natural and synthetic analogs of the antimitotic agent combretastatin: a structure-activity study. $\mathrm{Mol}$ Pharmacol 34: 200-208.

LOI M, MARCHIÒ S, BECHERINI P, DI PAOLO D, SOSTER M, CURNIS F, BRIGNOLE C, PAGNAN G, PERRI P, CAFFA I et al. (2010). Combined targeting of perivascular and endothelial tumor cells enhances anti-tumor efficacy of liposomal chemotherapy in neuroblastoma. J Control Release 145: 66-73.

LU, C., KAMAT, A. A., LIN, Y. G., MERRITT, W. M., LANDEN, C. N., KIM, T. J., SPANNUTH, W., ARUMUGAM, T., HAN, L. Y., JENNINGS et al. (2007). Dual targeting of endothelial cells and pericytes in antivascular therapy for ovarian carcinoma. Clin Cancer Res 13: 4209-4217.

LUAN, Y., and XU, W. (2007). The structure and main functions of aminopeptidase N. Curr Med Chem 14: 639-647.

MARCHIO, S., LAHDENRANTA, J., SCHLINGEMANN, R. O., VALDEMBRI, D. WESSELING, P., ARAP, M. A., HAJITOU, A., OZAWA, M. G., TREPEL, M., GIORDANO, R. J., NANUS, D. M., DIJKMAN, H. B., OOSTERWIJK, E., SIDMAN, R. L., COOPER, M. D., BUSSOLINO, F., PASQUALINI, R., and ARAP, $W$. (2004). Aminopeptidase A is a functional target in angiogenic blood vessels. Cancer Cell 5: 151-162.

MCDONALD, D. M., and CHOYKE, P. L. (2003). Imaging of angiogenesis: from microscope to clinic. Nat Med 9: 713-725.

MUELLER-KLIESER, W., VAUPEL, P., MANZ, R., and SCHMIDSEDER, R. (1981). Intracapillary oxyhemoglobin saturation of malignant tumors in humans. Int $\mathrm{J}$ Radiat Oncol Biol Phys 7: 1397-1404.

NAITO, S., VON ESCHENBACH, A. C., and FIDLER, I. J. (1987). Different growth pattern and biologic behavior of human renal cell carcinoma implanted into different organs of nude mice. J Natl Cancer Inst 78: 377-385.

NILSSON, F., KOSMEHL, H., ZARDI, L., and NERI, D. (2001). Targeted delivery of tissue factor to the ED-B domain of fibronectin, a marker of angiogenesis, mediates the infarction of solid tumors in mice. Cancer Res 61: 711-716.

PAKU, S., and PAWELETZ, N. (1991). First steps of tumor-related angiogenesis Lab Invest 65: 334-346.

PASQUALINI, R., KOIVUNEN, E., and RUOSLAHTI, E. (1997). Alpha v integrins as receptors for tumor targeting by circulating ligands. Nat Biotechnol 15: 542-546.

PASQUIER, E., ANDRE, N., and BRAGUER, D. (2007). Targeting microtubules to inhibit angiogenesis and disrupt tumour vasculature: implications for cancer treatment. Curr Cancer Drug Targets 7: 566-581.

PASTORINO, F., BRIGNOLE, C., DIPAOLO, D., NICO, B., PEZZOLO, A., MARIMPIETRI, D., PAGNAN, G., PICCARDI, F., CILLI, M., LONGHI et al. (2006). Targeting liposomal chemotherapy via both tumor cell-specific and tumorvasculature-specific ligands potentiates therapeutic efficacy. Cancer Res 66: 10073-10082.

PASTORINO, F., BRIGNOLE, C., MARIMPIETRI, D., CILLI, M., GAMBINI, C., RIBATTI, D., LONGHI, R., ALLEN, T. M., CORTI, A., and PONZONI, M. (2003a). Vascular damage and anti-angiogenic effects of tumor vessel-targeted liposomal chemotherapy. Cancer Res 63: 7400-7409.

PASTORINO, F., BRIGNOLE, C., MARIMPIETRI, D., SAPRA, P., MOASE, E. H., ALLEN, T. M., and PONZONI, M. (2003b). Doxorubicin-loaded Fab' fragments of anti-disialoganglioside immunoliposomes selectively inhibit the growth and dissemination of human neuroblastoma in nude mice. Cancer Res 63: 86-92.

PASTORINO, F., DI PAOLO, D., PICCARDI, F., NICO, B., RIBATTI, D., DAGA, A. BAIO, G., NEUMAIER, C. E., BRIGNOLE, C., LOI, M. et al. (2008). Enhanced antitumor efficacy of clinical-grade vasculature-targeted liposomal doxorubicin. Clin Cancer Res 14: 7320-7329.

PASTORINO, F., MARIMPIETRI, D., BRIGNOLE, C., DI PAOLO, D., PAGNAN, G. DAGA, A., PICCARDI, F., CILLI, M., ALLEN, T. M., and PONZONI, M. (2007). Ligandtargeted liposomal therapies of neuroblastoma. Curr Med Chem 14: 3070-3078. 
PERO, R. W., AXELSSON, B., SIEMANN, D., CHAPLIN, D., and DOUGHERTY, G. (1999). Newly discovered anti-inflammatory properties of the benzamides and nicotinamides. Mol Cell Biochem 193: 119-125.

PETTIT, G. R., SINGH, S. B., HAMEL, E., LIN, C. M., ALBERTS, D. S., and GARCIAKENDALL, D. (1989). Isolation and structure of the strong cell growth and tubulin inhibitor combretastatin A-4. Experientia 45: 209-211.

PILAT, M. J., and LORUSSO, P. M. (2006). Vascular disrupting agents. J Cell Biochem 99: 1021-1039.

PRICE, J. E., POLYZOS, A., ZHANG, R. D., and DANIELS, L. M. (1990). Tumorigenicity and metastasis of human breast carcinoma cell lines in nude mice. Cancer Res 50: 717-721.

RAN, S., DOWNES, A., and THORPE, P. E. (2002). Increased exposure of anionic phospholipids on the surface of tumor blood vessels. Cancer Res 62: 6132-6140.

RAN, S., HE, J., HUANG, X., SOARES, M., SCOTHORN, D., and THORPE, P. E. (2005). Antitumor effects of a monoclonal antibody that binds anionic phospholipids on the surface of tumor blood vessels in mice. Clin Cancer Res 11: 1551-1562.

RAN, S., and THORPE, P. E. (2002). Phosphatidylserine is a marker of tumor vasculature and a potential target for cancer imaging and therapy. Int $J$ Radiat Oncol Biol Phys 54: 1479-1484.

RAZAK, K., and NEWLAND, A. C. (1992). The significance of aminopeptidases and haematopoietic cell differentiation. Blood Rev 6: 243-250.

RIEMANN, D., KEHLEN, A., and LANGNER, J. (1999). CD13--not just a marker in leukemia typing. Immunol Today 20: 83-88.

ROBERTS, W. G., DELAAT, J., NAGANE, M., HUANG, S., CAVENEE, W. K., and PALADE, G. E. (1998). Host microvasculature influence on tumor vascular morphology and endothelial gene expression. Am J Pathol 153: 1239-1248.

RUOSLAHTI, E. (2002). Drug targeting to specific vascular sites. Drug Discov Today 7: 1138-1143.

SALMON, H. W., MLADINICH, C., and SIEMANN, D. W. (2006a). Evaluations of the renal cell carcinoma model Caki-1 using a silicon based microvascular casting technique. Technol Cancer Res Treat 5: 45-51.

SALMON, H. W., MLADINICH, C., and SIEMANN, D. W. (2006b). Evaluations of vascular disrupting agents CA4P and OXi4503 in renal cell carcinoma (Caki-1) using a silicon based microvascular casting technique. Eur J Cancer 42: 3073-3078.

SEON, B. K. (2002). Expression of endoglin (CD105) in tumor blood vessels. Int J Cancer 99: 310-311; author reply 312.

SEVICK, E. M., and JAIN, R. K. (1989). Geometric resistance to blood flow in solid tumors perfused ex vivo: effects of tumor size and perfusion pressure. Cancer Res 49: 3506-3512.

SHOJAEI, F., and FERRARA, N. (2008). Role of the microenvironment in tumor growth and in refractoriness/resistance to anti-angiogenic therapies. Drug Resist Updat 11: 219-230.

SIEMANN, D. W. (2004a). Therapeutic strategies that selectively target and disrupt established tumor vasculature. Hematol Oncol Clin North Am 18: 1023-1037, viii.

SIEMANN, D. W., BIBBY, M. C., DARK, G. G., DICKER, A. P., ESKENS, F. A., HORSMAN, M. R., MARME, D., and LORUSSO, P. M. (2005). Differentiation and definition of vascular-targeted therapies. Clin Cancer Res 11: 416-420.

SIEMANN, D. W., CHAPLIN, D. J., and HORSMAN, M. R. (2004b). Vascular-targeting therapies for treatment of malignant disease. Cancer 100: 2491-2499.

SIEMANN, D. W., and HORSMAN, M. R. (2009). Vascular targeted therapies in oncology. Cell Tissue Res 335: 241-248.

SIEMANN, D. W., MERCER, E., LEPLER, S., and ROJIANI, A. M. (2002). Vascular targeting agents enhance chemotherapeutic agent activities in solid tumor therapy. Int $J$ Cancer 99: 1-6.

SIEMANN, D. W., and SHI, W. (2003). Targeting the tumor blood vessel network to enhance the efficacy of radiation therapy. Semin Radiat Oncol 13: 53-61.
SINGH, R. K., BUCANA, C. D., GUTMAN, M., FAN, D., WILSON, M. R., and FIDLER, I. J. (1994). Organ site-dependent expression of basic fibroblast growth factor in human renal cell carcinoma cells. Am J Pathol 145: 365-374.

STEPHENSON, R. A., DINNEY, C. P., GOHJI, K., ORDONEZ, N. G., KILLION, J. J., and FIDLER, I. J. (1992). Metastatic model for human prostate cancer using orthotopic implantation in nude mice. J Natl Cancer Inst 84: 951-957.

TALMADGE, J. E., SINGH, R. K., FIDLER, I. J., and RAZ, A. (2007). Murine models to evaluate novel and conventional therapeutic strategies for cancer. Am J Pathol 170: $793-804$

TAYLOR, A. (1993). Aminopeptidases: structure and function. FASEB J 7: 290-298.

THALHEIMER, A., ILLERT, B., BUETER, M., GATTENLOHNER, S., STEHLE, D., GASSER, M., THIEDE, A., WAAGA-GASSER, A. M., and MEYER, D. (2006). Feasibility and limits of an orthotopic human colon cancer model in nude mice. Comp Med 56: 105-109.

THORPE, P. E. (2004). Vascular targeting agents as cancer therapeutics. Clin Cancer Res 10: 415-427.

THORPE, P. E., CHAPLIN, D. J., and BLAKEY, D. C. (2003). The first international conference on vascular targeting: meeting overview. Cancer Res 63: 1144-1147.

TOYOKUNI, S., OKAMOTO, K., YODOI, J., and HIAI, H. (1995). Persistent oxidative stress in cancer. FEBS Lett 358: 1-3.

TOZER, G. M., KANTHOU, C., and BAGULEY, B. C. (2005). Disrupting tumour blood vessels. Nat Rev Cancer 5: 423-435.

TOZER, G. M., KANTHOU, C., LEWIS, G., PRISE, V. E., VOJNOVIC, B., and HILL, S. A. (2008). Tumour vascular disrupting agents: combating treatment resistance. Br J Radiol 81 Spec No 1, S12-20.

TOZER, G. M., PRISE, V. E., WILSON, J., CEMAZAR, M., SHAN, S., DEWHIRST, M. W., BARBER, P. R., VOJNOVIC, B., and CHAPLIN, D. J. (2001). Mechanisms associated with tumor vascular shut-down induced by combretastatin A-4 phosphate: intravital microscopy and measurement of vascular permeability. Cancer Res 61: 6413-6422.

TOZER, G. M., PRISE, V. E., WILSON, J., LOCKE, R. J., VOJNOVIC, B., STRATFORD, M. R., DENNIS, M. F., and CHAPLIN, D. J. (1999). Combretastatin A-4 phosphate as a tumor vascular-targeting agent: early effects in tumors and normal tissues. Cancer Res 59: 1626-1634.

TREPEL, M., ARAP, W., and PASQUALINI, R. (2002). In vivo phage display and vascular heterogeneity: implications for targeted medicine. Curr Opin Chem Biol 6: 399-404.

TSUZUKI, Y., MOUTA CARREIRA, C., BOCKHORN, M., XU, L., JAIN, R. K., and FUKUMURA, D. (2001). Pancreas microenvironment promotes VEGF expression and tumor growth: novel window models for pancreatic tumor angiogenesis and microcirculation. Lab Invest 81: 1439-1451.

VAUPEL, P., and HOCKEL, M. (2000). Blood supply, oxygenation status and metabolic micromilieu of breast cancers: characterization and therapeutic relevance. Int J Oncol 17: 869-879.

VEENENDAAL, L. M., JIN, H., RAN, S., CHEUNG, L., NAVONE, N., MARKS, J. W., WALTENBERGER, J., THORPE, P., and ROSENBLUM, M. G. (2002). In vitro and in vivo studies of a VEGF121/rGelonin chimeric fusion toxin targeting the neovasculature of solid tumors. Proc Natl Acad Sci USA 99: 7866-7871.

VINCENT, L., KERMANI, P., YOUNG, L. M., CHENG, J., ZHANG, F., SHIDO, K., LAM, G., BOMPAIS-VINCENT, H., ZHU, Z., HICKLIN, D. J., BOHLEN, P., CHAPLIN, D. J., MAY, C., and RAFII, S. (2005). Combretastatin A4 phosphate induces rapid regression of tumor neovessels and growth through interference with vascular endothelial-cadherin signaling. J Clin Invest 115: 2992-3006.

WOGLOM, W. H. (1923). A critique of tumour resistance. J Cancer Res 7: 283-311.

ZAROVNI, N., MONACO, L., and CORTI, A. (2004). Inhibition of tumor growth by intramuscular injection of CDNA encoding tumor necrosis factor alpha coupled to NGR and RGD tumor-homing peptides. Hum Gene Ther 15: 373-382. 


\section{Further Related Reading, published previously in the Int. J. Dev. Biol.}

The role of pericytes in angiogenesis

Domenico Ribatti, Beatrice Nico and Enrico Crivellato

Int. J. Dev. Biol. (2011) 55: 261-268

Challenges and strategies for generating therapeutic patient-specific hemangioblasts and hematopoietic stem cells from human pluripotent stem cells

Ann Peters, Paul W. Burridge, Marina V. Pryzhkova, Michal A. Levine,Tea-Soon Park, Christopher Roxbury, Xuan Yuan, Bruno Péault and Elias T. Zambidis

Int. J. Dev. Biol. (2010) 54: 965-990

Parallels in invasion and angiogenesis provide pivotal points for therapeutic intervention

Suzanne A. Eccles

Int. J. Dev. Biol. (2004) 48: 583-598

Matrix metalloproteinases in cancer: from new functions to improved inhibition strategies Alicia R. Folgueras, Alberto M. Pendás, Luis M. Sánchez and Carlos López-Otín Int. J. Dev. Biol. (2004) 48: 411-424

Angiogenesis and apoptosis are cellular parameters of neoplastic progression in transgenic mouse models of tumorigenesis G Bergers, D Hanahan and L M Coussens Int. J. Dev. Biol. (1998) 42: 995-1002

The chick embryo chorioallantoic membrane as a model for in vivo research on angiogenesis D Ribatti, A Vacca, L Roncali and F Dammacco

Int. J. Dev. Biol. (1996) 40: 1189-1197

5 yr ISI Impact Factor $(2009)=3.253$

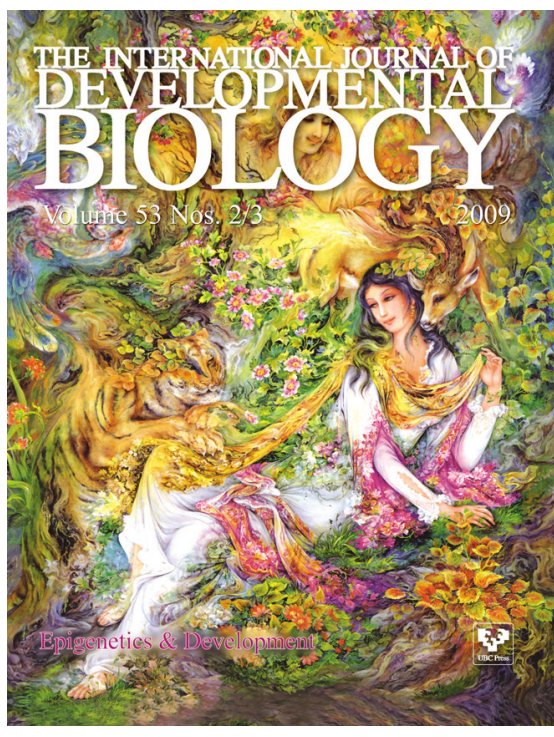

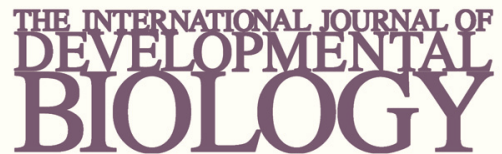

Volume 54 Nos. 6/7
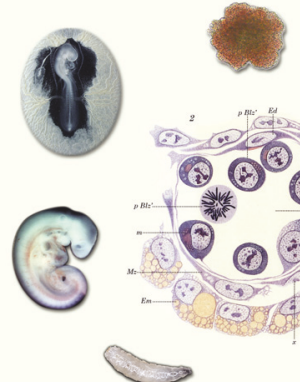

Special Issue

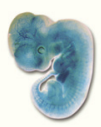

Developmental Hematopoiesis

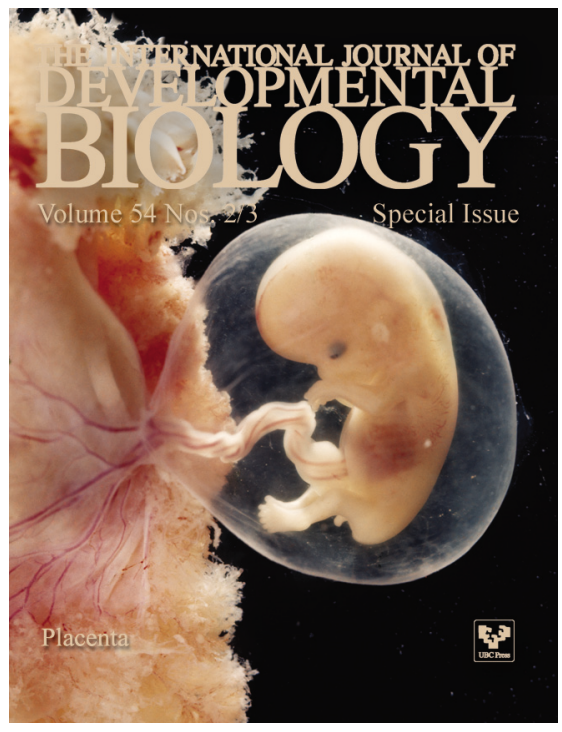

